\title{
DIESELGATE: A CORPORAÇÃO NO BANCO DOS RÉUS
}

\author{
DIESELGATE: THE CORPORATION IN THE DOCK
}

\author{
Recebido em: 03/08/2018 - Aprovado em: 21/12/2018 \\ Avaliado pelo sistema double blind review \\ Editor Científico: Edson Sadao Iizuka \\ DOI 10.13058/raep.2019.v20n2.1045
}

\section{CINTIA RODRIGUES DE OLIVEIRAMEDEIROS cintia@ufu.br}

\author{
Universidade Federal de UberLÂNDIA
}

\begin{abstract}
RESUMO
Este caso para ensino em administração desafia a perspectiva tradicional que se dedica aos casos de melhores práticas e de decisões tomadas pelos gestores nas atividades gerenciais. Nessa direção, o objetivo deste caso de ensino é provocar reflexões e debate sobre o dark side de organizações contemporâneas, mais especificamente, sobre um crime corporativo. O caso em evidência é o chamado dieselgate, um crime protagonizado pela corporação alemã Volkswagen, na falsificação de resultados de emissões de poluentes em motores a diesel. Diferentemente de casos para ensino que partem de um dilema do gestor, este caso é focado nas práticas corporativas prejudiciais ao meio ambiente, nos fatores que estimulam as empresas a agirem de forma criminosa e como essas condições podem ser alteradas.
\end{abstract}

Palavras-chave: Crime corporativo. Dark side. Dieselgate.

\begin{abstract}
This case for teaching in management challenges the traditional perspective that is dedicated to the cases of best practices and decisions faced by the managers in the managerial activities. In this direction, the purpose of this teaching case is to provoke reflections and debate on the dark side of contemporary organizations, more specifically, on corporate crime. The case in point is the so-called "dieselgate", a crime carried out by the German corporation Volkswagen, in the falsification of pollutant emissions results in diesel engines. Unlike teaching cases that stem from a manager's dilemma, this case focuses on corporate practices that are detrimental to the environment, on factors that encourage companies to act in a criminal manner, and how those conditions can be altered.
\end{abstract}

Keywords: Corporate Crime. Dark side. Dieselgate. 
Our company was dishonest, with the EPA and the California Air Resources board, and with all of you and in my German words, we have totally screwed up [...] We have to make things right, with the government, the public, our customers, our employees and also very important, our dealers [...] Along with our German headquarters we are committed to do what must be done, and to begin to restore your trust $[\ldots]$ (SEIB, 2015).

O trecho acima faz parte do discurso proferido por Michael Horn, presidente-executivo do Grupo Volkswagen da América, durante o lançamento do Passat 2016, depois que a montadora alemã foi acusada de falsificar os testes de emissões dos EUA. Trata-se de um pedido de desculpas por um ato intencional, cometido para alcançar os objetivos corporativos, com consequências drásticas para o meio ambiente e a sociedade.

Escândalos corporativos como esse têm se tornado cada vez mais comuns, o que enseja reflexões sobre a atuação das corporações e seu poder sobre nações e sociedades. Algumas questões a se levantar são: porque as organizações provocam danos e prejuízos? Qual é a responsabilidade dos top managers quando isso acontece? Neste caso, especificamente, uma fraude foi cometida no curso dos processos operacionais da empresa, configurando-se em uma irresponsabilidade socioambiental, visto as consequências do ato para o meio ambiente, além de ser uma conduta criminosa.

\section{Pressão para alcançar objetivos corporativos: uma cultura arrogante}

O caso tornou-se público em setembro de 2015, nos Estados Unidos, porém, desde antes suspeitava-se sobre a fraude praticada para responder às pressões do governo norte-americano, iniciadas em 2004, quanto aos altos padrões exigidos para emissão de óxido de nitrogênio (NOx), um poluente emitido na combustão do diesel. Em 2009, a Volkswagen anunciou a fabricação de carros com diesel limpo, produzidos com um sistema diferente para cumprir as regras norte-americanas, que eram muito mais rigorosas do que as europeias, pois permitia apenas cerca de um sexto do que a Europa permitia. Esse sistema utiliza-se de motores EA189, que dis- 
pensam o uso de ureia na mistura de gases e água, o que ameniza o efeito prejudicial do óxido de nitrogênio (Nox) no meio ambiente (HOTTEN, 2015; JUSTIÇA, 2018).

A estratégia da VW para aumentar as vendas nos Estados Unidos, que estavam em queda, nasceu do então CEO Bernd Pischetsrieder e continuou quando Winterkorn o substituiu, em janeiro de 2007. Winterkorn foi o protegido do presidente do conselho de supervisão da VW, Ferdinand Piëch, que havia sido CEO da empresa de 1993 a 2002, sendo considerado o personagem mais influente da história da empresa. Um talentoso engenheiro e líder profético, ele também era implacável: Piëch se gabou de sua disposição em demitir executivos se eles não cumprissem as metas. No início de 2008, a VW anunciou o planejamento estratégico de 10 anos, o qual estabelecia um objetivo de vendas da empresa para superar a General Mortos e a Toyota, até 2018, que levasse a empresa à liderança na fabricação de automóveis no mundo. A pressão pelo cumprimento de metas pode levar os envolvidos a tomar decisões sem analisar as consequências, por exemplo, nesse caso, o ex-engenheiro da Audi, Pamio, acusa os top managers de terem conhecimento que os motores não conseguiriam cumprir os parâmetros definidos pelas autoridades norte-americanas e europeias (EWING, 2017).

Esse acontecimento evidencia: uma cultura corporativa arrogante e corrupta, protegida pelo papel vital desempenhado pela empresa na economia alemã; o relacionamento próximo de seus funcionários com os políticos alemães; e seu status incomum quase-público (o estado da Baixa Saxônia controla $20 \%$ de suas ações votantes). Piëch sobreviveu a grandes escândalos, incluindo um debate de espionagem corporativo na década de 1990, que terminou em um acordo de US \$ 100 milhões com a General Motors, e um escândalo de trabalho de quase dezenas de décadas que surgiu em 2004, quando a empresa fez pagamentos ilegais a representantes trabalhistas e políticos.

\section{Prenúncios do crime e a negação}

Em 2013, o baixo nível de emissões de veículos da VW com motor a diesel chamou a atenção do Conselho Internacional de Transporte Limpo (CITL), 
um grupo independente. Em conjunto com a Universidade de West Virginia, o CITL iniciou um projeto para "estudar o sistema para mostrar como o diesel poderia ser um combustível limpo". A partir de então, três carros foram analisados: dois da marca VW, um da marca BMW. Nos carros da primeira, percebeu-se que havia uma diferença entre o nível de emissão do NOx nos testes em laboratório e aqueles observados no estudo das ruas. Com esses resultados, em 2014, o CITL e a Universidade de West Virginia comunicaram a Agência de Proteção Ambiental (EPA) norte-americana e o Conselho de Emissões da Califórnia (CARB) quanto aos resultados dos testes comparativos. Sendo a empresa comunicada, essa acusou o estudo de ser falso culpando questões técnicas. Apesar da negação, a empresa optou por fazer um recall de 500 mil carros nos EUA, com a promessa de resolver o caso (JUSTIÇA, 2018).

\section{Da suspeita à acusação de Crime}

Continuando os testes, a CARB e a EPA tentavam descobrir o motivo das diferenças de dados encontrados nos laboratórios e nas ruas. Em 2015, a EPA descobriu um software instalado na central eletrônica dos carros da VW, que alterava as emissões de poluentes nos veículos submetidos a vistorias. O software funcionava da seguinte forma: depois de rastrear a posição do volante, a velocidade do veículo, o tempo que o carro estava ligado e a pressão barométrica, o dispositivo baixava os poluentes emitidos por reconhecer uma condição de teste, e, em condições normais, os controles do escape são desligados e os carros poluem além dos indicadores permitidos. Em 18 de setembro de 2015, a empresa foi acusada pelo governo norte-americano de fraudar os dados de emissões de gases poluentes para atender a regulamentação do país, abrindo um processo criminal (HOTTEN, 2015; JUSTIÇA, 2018).

O Departamento de Justiça dos Estados Unidos acusou Martin Winterkorn e outros de conspiração, em 14 de março de 2018: 2015, DORENKAMP, NEUSSER, HADLER, GOTTWEIS, PETER, WIN- 
TERKORN, and their co-conspirators agreed to defraud U.S. regulators and U.S. customers, and violate the Clean Air Act, by misleading U.S. regulators and U.S. customers about whether the Subject Vehicles and the Porsche Vehicles complied with U.S. emissions standards (THE UNITED STATES, 2018, p. 13).

Em 13 de junho de 2018, a Volkswagen foi condenada pela Promotoria de Brauschweig, na Alemanha, a pagar a multa de 1 bilhão de euros, pela manipulação das emissões de gases nos motores a dieses. A empresa não contestou a condenação, declarando-se culpada das acusaçoes (ESCÂNDALO, 2018).

\section{Desculpas e lamentos}

Com as notícias estampadas nos principais veículos de comunicação do mundo, as reações dos executivos foram diversas. Em 20 de setembro de 2015, o presidente-executivo Martin Winterkorn divulga uma nota lamentando: "Pessoalmente e profundamente, lamento muito que tenhamos quebrado a confiança de nossos clientes e do público" e anunciou sua renúncia três dias depois, dizendo que não estava envolvido na fraude. $\mathrm{O}$ Conselho da empresa afirmou que o executivo "não tinha conhecimento da manipulação de dados de emissões. A Volkswagen não tolera nenhuma violação, nem de leis, nem de normas" (JUSTIÇA, 2018).

Em 21 de setembro de 2015 é a vez de Michael Horn, o presidente da empresa nos USA, que assumiu a culpa da empresa durante o lançamento do novo Passat, em Nova York, embora tenha afirmado não ter tido conhecimento dos fatos. Entretanto, a investigação encontrou e-mails dirigidos ao então presidente alertando sobre o problema. Em 23 de setembro, um novo presidente assume o comando do grupo e anuncia uma reorganização. Em 2016, o novo presidente executivo pede desculpas publicamente, dizendo: "Não somos uma marca criminosa" e anuncia um investimento de US\$ 900 milhões nos USA (JUSTIÇA, 2018).

Somente em dezembro de 2015, a VW fez uma comunicação oficial afirmando que a fraude começou em 2005, com a adoção de uma tática agressiva no segmento diesel para o mercado americano, "mas ainda não 
há provas de envolvimento de membros da diretoria ou do conselho" (JUSTIÇA, 2018).

De acordo com o documento de acusação do Departamento de Justiça norte-americano, os promotores norte-americanos entenderam que Winterkorn, ainda que não tenha ordenado seus subordinados a não divulgarem a fraude, concordou em continuar a enganar as autoridades norte-americanas (THE UNITED STATES, 2018).

\section{Governo, reguladoras e justiça}

Os depoimentos no Congresso norte-americano começaram em outubro de 2015, sendo o primeiro executivo da VW a depor o então presidente Michael Horn, que declarou saber que as emissões de automóveis a diesel da montadora eram superiores aos permitidos pelas normas dos EUA. O presidente acrescenta que soube da fraude no início de setembro, em uma reunião com os agentes reguladores norte-americanos. Ainda em 2015, Alemanha, França e Reino Unido anunciam medidas para refazer os testes de emissões, (JUSTIÇA, 2018).

Em 2017, houve condenações e prisões de executivos: Oliver Schmi$\mathrm{dt}$, chefe de departamento que deveria cumprir as normas regulatórias, foi condenado a 7 anos de prisão, em dezembro de 2017 (MARQUET, 2017; GOLDMAN; TABUCHI; EWING, 2017; JUSTIÇA, 2018). Além da condenação para a prisão, o juiz norte-americano ordenou que Schmidt pagasse uma penalidade criminal de U $\$ 400.000$, por conspiração para fraudar contra os Estados Unidos, cometer fraude eletrônica e violar o Clean Air Act (THE UNITED STATES, 2017). Outros cinco executivos foram indiciados pelo departamento de Justiça norte-americano por acusações de conspiração e intenção de fraudar (MARQUET, 2017).

Na sentença condenatória de Oliver Schmidt, o agente especial do FBI encarregado do caso pronunciou que "os americanos esperam que as corporações sigam leis e regulamentos destinados a proteger os consumidores e o meio ambiente" (THE UNITED STATES, 2017). 


\section{Ações tomadas pela empresa}

Em outubro de 2015, a montadora informa que fará um recall de 8,5 milhões de carros para reverter o problema, começando em 2016, na Alemanha. Nos EUA, a solução do recall foi aprovada pelo governo norte-americano somente em 2017. Além disso, a montadora afirmou que está em desenvolvimento na Alemanha uma atualização do software fraudulento(JUSTIÇA, 2018) e seu presidente afirma que "lamenta profundamente o comportamento que deu origem à crise do diesel. Desde que tudo isso veio à tona, trabalhamos incansavelmente para tornar as coisas corretas para nossos clientes afetados e já conseguimos algum progresso neste caminho" (MARQUET, 2017).

Os prejuízos financeiros da empresa começaram a ser anunciados ainda em outubro de 2015: "O grupo VW anuncia seu primeiro prejuízo trimestral em pelo menos 15 anos. O resultado é afetado pela reserva de $€$ 6,7 bilhões para cobrir custos com a fraude". O prejuízo informado foi de 1,3 bilhão de euros em 2015. Entre outros prejuízos, contabilizam-se:

a. as multas do Ibama e do Procon-SP, da filial brasileira da empresa, em R $\$ 50$ milhões e R \$ 8,5 milhões, respectivamente;

b. o programa de compensação financeira oferecido pela empresa aos clientes que adquiriram carros com o motor TDI (turbodiesel) no valor de US\$1.000;

c. processo judicial civil impetrado pelo Departamento de Justiça norte-americano com implicações de penalidades que podem chegar a US4 48 bilhões;

d. dezenas de grandes acionistas ameaçaram processar a montadora para obterem compensação pela queda das suas ações provocadas pela fraude cometida; e

e. acordo de US\$ 10 bilhões para por fim a processos movidos por consumidores nos EUA (JUSTIÇA, 2018).

Para se ter uma ideia das consequências dessa fraude:

- 482 mil veículos com motores a diesel violam os padrões federais, nos Estados Unidos, entre eles Jetta, Beetle (chamado de Fusca 
no Brasil), Golf, Passat e o Audi A3 da marca que pertence ao grupo Volkswagen. Os veículos foram fabricados entre 2009 e 2015;

- foram 11 milhões de veículos a diesel em todo o mundo, em modelos de várias marcas pertencentes ao grupo

- Em janeiro de 2018, a VW comemorou o recorde anual de carros vendidos em 2017, superando a marca de 6.23 milhões de unidades em todo o mundo, obtida em 2017 (JUSTIÇA, 2018).

\section{Desfecho: a admissão da culpa}

Em 2017, a empresa admitiu sua culpa no crime que resultou em prejuízos para o meio ambiente, clientes e acionistas. Segundo o Departamento de Justiça dos Estados Unidos,

Schmidt admitiu ainda que sabia, durante a sua particpação na conspiração, que os veículos "diesel limpo" da VW estavam sendo comercializados para o público como sendo ecologicamente corretos e promovendo maior economia de combustível ao mesmo tempo em que cumpria as regulamentações ambientais dos EUA. Schmidt sabia que os veículos a diesel da VW não estavam em conformidade com os padrões e regulamentos dos EUA e que essas representações feitas a clientes domésticos eram falsas, admitiu ele (THE UNITED STATES, 2017).

A empresa ainda informou, em junho de 2016 , ter reservado " 7,8 bilhões de euros para recomprar e reparar os veículos fora das legislações ambientais. E outros 7 bilhões para cobrir custos com multas e processos legais no mundo inteiro". No acordo bilionário, a VW prometeu pagar US $\$ 4,3$ bilhões em multas de modo a findar os processos civis e criminais contra ela nos EUA e, ainda, suas operações serão supervisionadas por um monitor independente. Outros acordos foram realizados: US\$ 157 milhões para indenizar 10 estados, incluindo Nova York, Massachusetts e Pensilvânia, e assim saldar as penas por violar as normas sobre emissão de gases poluentes; US\$ 1,2 bilhão para consertar ou recomprar 80 mil carros com motor 3.0 diesel; US\$ 154 milhões ao estado da Califórnia, além dos US\$ 533 milhões acertados anteriormente (JUSTIÇA, 2018). 


\section{NOTAS DE ENSINO}

\section{Objetivos Educacionais}

A proposta deste caso de ensino é levar a estudantes de gestão materiais que estimulem suas reflexões sobre as consequências das suas decisões nas atividades empresariais quando se encontrarem confrontados com práticas criminosas e ilegais. Nessa direção, propõe-se para este caso os seguintes objetivos educacionais:

a. Reconhecer as condições contextuais, econômicas e organizacionais que antecedem os crimes corporativos;

b. Analisar as consequências e o alcance de condutas corporativas criminosas;

c. Compreender a literatura orientada para o questionamento da ciência do management;

d. Argumentar sobre os fatores que encorajam e aqueles que desencorajam o engajameto da empresa em crimes corporativos;

e. Propor estratégias de mudança para situações semelhantes à apresentada no caso, de modo a evitar práticas corporativas criminosas.

\section{Utilização do caso}

O caso pode ser aplicado em cursos da área de administração e negócios, bem como em cursos de gestão pública, em nível de graduação e pós-graduação. Disciplinas como Liderança, Cultura Organizacional e Mudança, Poder nas Organizações, Teoria das Organizações, Ética, Gestão Pública e Estudos Críticos em Gestão têm potencial para explorar o caso em diversos aspectos, principalmente, considerando que crimes corporativos não são acidentais, mas, sim, fazem parte das operações corporativas, podendo ser intencionais. O caso também é interessante para ser discutido em cursos e treinamentos para executivos e gerentes de nível médio e alto, do setor público e privado. 


\section{Plano de aula sugerido}

O caso pode ser aplicado em quatro (4) horas/aula, depois de concluídas as aulas teóricas sobre o tema que será pano de fundo para a discussão: seja ética, comportamento organizacional, gestão pública, gestão empresarial, cultura, poder, etc. $\mathrm{O}(\mathrm{a})$ professor (a) pode recomendar a leitura dos textos de Fournier e Grey (2006) e da metáfora da dominação (MORGAN, 1996) para a aproximação dos estudantes com os estudos críticos em administração. Então, para a aplicação do caso, sugerimos iniciar pela leitura individual do caso na sala de aula, na primeira aula, para que as informações estejam mais presentes no momento de dicussão. Em seguida, na segunda aula, o caso deverá ser discutido em pequenos grupos preparando-se para o debate, quando o(a) professor(a) explicará que os(as) participantes devem se posicionar sobre o caso e seus desdobramentos, tecendo seus argumentos com base no caso apresentado e a leitura do material indicado. $\mathrm{O}(\mathrm{a})$ professor(a) deverá então estimular os(as) estudantes a fazerem uma pesquisa sobre o caso para obterem informações adicionais, podendo, nesse momento, indicar o primeiro episódio "Emissões Mortais" do documentário "Na rota do dinheiro sujo", da Netflix. Esse episódio explica a fraude, de forma bastante didática, desde a descoberta quase acidental do crime pelo ICTL, os emails que orientavam técnicos da empresa para protelar as respostas dadas às entidaes de pesquisa, até depoimentos de ex-executivos na justiça norte-americana. O documentário mostra o cinismo dos executivos da empresa ao lidar com esse caso, pouco se importando com os milhares de pessoas afetadas pelas emissões tóxicas. Na terceira e quarta aulas, o(a) professor(a) estimula os estudantes a debaterem sobre organizações e modelos de gestão alternativos que desencorajem tais práticas.

\section{Questões sugeridas para discussão em aula}

1. Quais são as condições contextuais e organizacionais que permitiram e encorajaram os envolvidos a se engajarem na falsificação de resultados das emissões de poluentes?

2. Quais práticas e estruturas formais e informais da VW permitiram e encorajaram a fraude? 
3. Quais fatores organizacionais poderiam ter desencorajado a fraude e os motivos que não o fizeram?

4. Como você analisa a atuação de governos e agências no caso?

5. Como você analisa as condutas dos executivos e gestores em relação ao caso?

6. Como você analisa a atuação das equipes técnicas e de P\&D? Elas cumprem os padrões legais ou cumprem ordens dos superiores sem questionamento sobre sua (i)legalidade?

7. Como você analisa a participação dos investidores (acionistas) no caso?

8. Discuta as inter-relações entre os níveis formais e informais, entre governos, agências e empresas para criar organizações e modos alternativos de gestão que favoreçam condições que encorajem os trabalhadores e executivos a falarem sobre comportamentos e práticas criminosas bem como aquelas inadequadas moralmente.

\section{Fontes de dados}

O caso foi elaborado com base em fontes secundárias disponíveis na internet, incluindo: reportagens de jornais e revistas, em sua versão eletrônica, e vídeos contendo as declarações de executivos da empresa e outros envolvidos no caso. Dada a repercussão do escândalo, encontramos um vasto material, o que nos levou a delimitar o material publicado nas seguintes fontes: Jornal Folha de S.Paulo, Revista Forbes, BBC News, Globo.com, New York Times, no website da Volkswagen International e no Departamento de Justiça dos Estados Unidos. Não houve a inclusão de dados fictícios, os desdobramentos também são reais. Nas referências bibliográficas estão relacionados os acessos para o material considerado na elaboração do caso. $\mathrm{O}$ uso de fontes secundárias foi apropriada para este caso para ensino tendo em vista a sua natureza, visto tratar-se de um assunto sobre o qual as empresas, em geral, preferem silenciar-se para não dar margem a mais especulações. Além disso, considerou-se a impossibilidade de obtenção de acesso a muitos dos protagonistas do caso. 


\section{Análise do caso}

Este caso pode ser discutido sem referências a abordagens conceituais e teóricas, no entanto, uma análise que estimule estudantes a refletir sobre condutas criminosas das corporações exige recursos conceituais específicos. Entre outras possilidades de abordagens conceituais para analisar o caso, sugerimos leituras orientadas para a compreensão de:

Corporações e o dark side - Para que os(as) estudantes se posicionem sobre o caso, é recomendada uma visita às perspectivas críticas à administração, partindo da ideia de que, no mesmo compasso em que as corporações produzem bens e serviços para a sociedade, essas produzem ações prejudiciais que resultam em altos custos sociais e ambientais. Isso implica que as mesmas características de um sistema que produz o lado brilhante ${ }^{1}$ (bright side) são capazes de gerar o lado sombrio (dark side) da organização que, geralmente, não é central para as teorias organizacionais (VAUGHAN, 1999) ensinadas nos cursos de gestão. Isso implica em fundamentar a natureza das corporações, dos objetivos corporativos e como esse modelo de negócios amplia o poder das grandes corporações potencializando a existência de "organizações que matam" (MEDEIROS; ALCADIPANI, 2017).

O surgimento das corporações no século XIX mudou os mecanismos de propriedade de empresas, inclusive, no âmbito legal, e essas, rapidamente, entre 1840 e 1860, tornaram-se o modelo preferido pelos capitalistas para a organização de negócios. Corporações são definidas como a instituição econômica e social que opera negócios em larga escala (big business), em um sistema de livre iniciativa (free-enterprise) capaz de tornar possível o desenvolvimento de operações em larga escala no âmbito dos transportes, comunicações, distribuição e produção, o que exige grandes quantidades de capital (CAREY JR., 2011).

Nos anos 1870, as principais corporações, na maioria das indústrias, se orientavam para reduzir a competição e aumentar seus lucros por meio de uma combinação horizontal que lhes permitiam o controle da matéria-prima e do mercado, além de outras vantagens. Já naquela época, as

1 No sentido de: o que se pode ver 
corporações foram acusadas de fixação de preços, exploração e outros abusos, resultando em uma reação política do governo norte-americano que instituiu novas formas de regulação para esse tipo de organização, no final do século XIX (CAREY JR., 2011). A característica principal desse tipo de organização de empresas é sua capacidade de influência e poder sobre uma ampla e extensa abrangência geográfica, cultural e social, além das possibilidades de obtenção de maiores lucros (CLINARD et al., 1979). Conforme a análise Barley (2007, p. 214), as corporações influenciam as instituições sociais de três modos: (1) "promovendo legislação que beneficia cidadãos corporativos em detrimento dos cidadãos"; (2) "dificultando ou redirecionando a criação de agências para proteger o bem público dos atos das corporações e das externalidades que elas criam"; e (3) "privatizando funções que têm sido historicamente desempenhadas pelos governos local, estadual e federal".

Grandes negócios implicam no alto poder econômico nas mãos de poucos; empregados têm poder limitado de barganha com seus empregadores e são mais vulneráveis às crises econômicas, além de serem forçados a aceitar condições de trabalho precárias, com longas horas de trabalho e baixos salários (PEARCE; TOMBS, 1999; CAREY JR., 2011). As corporações contemporâneas gozam do poder da mobilidade, o que lhes permite escolher os recursos, as condições e a localização de suas operações de modo a obterem condições de produção vantajosas, ao mesmo tempo em que eliminam quaisquer tipos de limitações e restrições, e, cada vez mais, "a economia mundial será ainda mais dominada pelas corporações internacionais abertas" (SOROS, 2001, p. 199) que, cada vez mais, prestam menos atenção aos interesses sociais e ambientais.

\section{Criminalidade corporativa}

Para a análise deste caso, como o foco é a gestão, deve-se buscar a compreensão de crime corporativo na sua concepção sociológica, a despeito das controvérsias sobre o termo. Vários autores propõem conceitualizações, sendo o de Kramer (1984, p. 18) apropriado para a análise do caso: "atos criminais (de omissão ou comissão) que são resultado de ações tomadas de- 
liberadamente (ou negligência culposa) por aqueles que ocupam posições na estrutura da organização como executivos ou gerentes". Para o autor, as decisões de cometer o crime corporativo baseiam-se na organização, sendo "tomadas em acordo com os objetivos normativos (principalmente lucro corporativo), procedimentos operacionais padrões, e normas culturais da organização - e são destinadas a beneficiar a própria corporação" (KRAMER, 1984, p. 18).

O estudo dos antecedentes dos crimes corporativos tomou várias direções, ocasionando em um farto material para analisar as motivações das corporações para engajarem-se em condutas criminosas. Szwajkowski (1985), por exemplo, propõe a análise dos estímulos à ilegalidade organizacional por meio da integração teórica de três elementos ou variáveis determinantes para a sua ocorrência que, comumente, convergem nos estudos sobre o tema, a saber: (1) ambiente (pressões, necessidade ou recessão econômica); (2) estrutura (corporativa, industrial ou legal); e (3) processo de escolha interna (patologia, intenção ou exploração proativa).

O modelo de Baucus e Near (1991) para análise do processo do comportamento corporativo ilegal considera os antecedentes em três níveis: ambientais, internos e situacionais. Quanto aos antecedentes ambientais que criam condições para a ação gerencial criminosa, as autoras citam: a escassez dos recursos aumenta a incerteza ambiental, levando os gerentes a ações no sentido de reduzir essa incerteza; o dinamismo do ambiente exige respostas mais rápidas e não padronizadas; a heterogeneidade do ambiente torna as ações organizacionais mais complexas em virtude da diversidade de organizações e de firmas individuais atuando no mesmo ambiente. Os antecedentes internos são: o baixo desempenho organizacional; o grande porte da organização; e a baixa folga organizacional. Como antecedentes situacionais, Baucus e Near (1991) consideram: violações anteriores da lei, que podem encorajar a criminalidade corporativa; o tipo de indústria, que pode favorecer a criminalidade corporativa em virtude de características do setor; e o tipo de violação, pois, como defendem as autoras, é possível que uma combinação dos antecedentes possa levar a um tipo de violação específica. 
Posteriormente, Baucus (1994) amplia a compreensão da ilegalidade corporativa ao desenvolver um modelo que considera as pressões, as oportunidades e a predisposição como antecedentes do comportamento ilegal e as características individuais como variável moderadora. O modelo do processo de ilegalidade corporativa proposto por Baucus (1994) considera, ainda, os tipos de ilegalidade corporativa, os quais são divididos em duas categorias: o comportamento ilegal intencional e não intencional.

Além desses estudos apresentados sobre os antecedentes da criminalidade corporativa, outros pesquisadores (ver MCKENDALL; WAGNER, 1997; MON, 2002; MacLEAN, 2008) abrangeram variáveis internas e externas à organização, e alguns deles buscaram compreender a criminalidade corporativa pela análise das características institucionais, organizacionais e individuais. De modo geral, é comum nos estudos os seguintes fatores antecedentes: a pressão por resultados, a busca pelo desempenho superior, na ênfase dos objetivos corporativos e nos procedimentos e padrões operacionais, portanto, fatores institucionais e organizacionais influenciam a ocorrência ou não do crime corporativo. Nesse sentido, Michalowski e Kramer $(1987,2007)$ propõem um framework analítico para integrar a teoria do crime organizacional, que liga os três níveis de análise (individual, organizacional e institucional) a três catálises para a ação, quais sejam: motivo ou pressões para desempenho; estrutura de oportunidade, e a operacionalidade do controle. No que concerne às condições que criam as pressões por resultados, essas surgem quando indivíduos, inclusive acionistas/investidores, ou organizações colocam demandas urgentes ou restrições sobre uma empresa, fazendo com que seus empregados respondam de alguma forma, ou mesmo quando fornecedores, credores, agências reguladoras e outros agentes usam a disponibilidade de recursos, ameaça de sanções ou outros meios para forçar uma firma a agir de determinado modo, engajando-se em práticas ilegais (BAUCUS, 1994). Desse modo, a criminalidade corporativa é um fenômeno social complexo, cuja compreensão não prescinde de um olhar mais aprofundado sobre o modo pelo qual as corporações se constituem em atores sociais que intermediam as forças institucionais e a ação dos indivíduos. 
Os custos e consequências dos crimes corporativos são aspectos de alta relevância. Os crimes comuns trazem consequências para indivíduos e comunidades, porém o crime corporativo acarreta um conjunto de danos e prejuízos que vão além daqueles, atingindo proporções inestimáveis (CLINARD et al., 1979; PAYNE, 2012). Embora esses custos não sejam facilmente identificáveis e mensuráveis, haja vista que em muitos desses crimes não são relatados os prejuízos reais para não constranger os negócios envolvidos, diversos autores contribuem com o assunto na forma de classificá-los e, assim, tornar mais fácil a identificação das dimensões atingidas. Ainda sobre esse aspecto, Clinard et al. (1979) ressaltam que as estatísticas oficiais quanto a esses custos não levam em conta doenças provocadas pela poluição ambiental, a venda de produtos que provocam danos aos consumidores, as condições de trabalho potencialmente perigosas por exposição a produtos tóxicos, traumas psicológicos da vitimização e o chamado crime social da fábrica para se referir à alienação do trabalho, à erosão da confiança nas instituições, que provoca um processo de "deslegitimação", e o cinismo que emerge no âmbito das instituições protagonistas dos crimes, sendo esses custos, portanto, subdimensionados.

Para discutir a atuação dos executivos na falsificação, um importante aporte teórico para ser discutido é sobre os top managers, aqueles que têm o poder de decisões estratégicas nas corporações. Daboub et al. (1995) introduzem as características da equipe de executivos da alta direção não como um preditor do crime corporativo, mas como um fator que indica o grau em que as pressões crescentes dos fatores antecedentes podem levar à ilegalidade, visto que o papel desempenhado pelos executivos na condução da empresa tem influência nas decisões relacionadas aos fatores organizacionais e ambientais e, consequentemente, pode neutralizar ou estimular a ocorrência da ilegalidade.

Um aspecto que também deve estar no centro das reflexões dos estudantes quanto ao caso são as reações da corporação manifestando suas desculpas, o que torna pertinente discutir o "desengajamento moral" das corporações quando as práticas criminosas vêm a público. O desengajamento moral da corporação, por meio de mecanismos ou manobras para 
minimizar a reprovação de trabalhadores e da sociedade em geral, reduz os efeitos negativos das práticas criminosas e ilegais, diminuindo as possibilidades de denúncias e boicotes de consumidores (MEDEIROS; SILVEIRA; OLIVEIRA, 2018).

O conceito de Michalowski e Kramer (2007) para state-corporate crime contribui para o entendimento das relações entre governos e corporações. Esse conceito que, de certo modo, pode ser uma tipologia de crime corporativo, compreende a intersecção entre governos e corporações para produzir danos sociais e consiste em "ações ilegais ou socialmente prejudiciais que ocorrem quando uma ou mais instituições de governança política perseguem um objetivo em cooperação direta com uma ou mais instituições de produção e distribuição econômica" (MICHALOWSKI; KRAMER, 2007 , p. 270). As relações interorganizacionais desviantes têm como participantes agências do governo e corporações de negócios, as quais agem dentro do sistema capitalista, com consequências prejudiciais. O state-corporate crime ocorre de duas formas distintas: quando corporações contratadas pelo governo engajam em práticas desviantes, ou têm a aprovação do governo para tal; e quando as instituições regulatórias governamentais falham em restringir as atividades de negócios desviantes.

Dada a importância contemporânea da ética nos negócios e da responsabilidade social corporativa, ter empregados(as) que valorizem comportamentos morais e obedecem a lei é um componente importante para que as práticas criminosas deixem de ocorrer. Apesar das restrições formais e legislativas para punir práticas criminosas, elementos informais devem ser considerados para criar e sustentar uma organização em que empregados(as) sintam-se desencorajados(as) a se engajar em tais práticas e, até, denunciá-las. Vários são os estudos que se orientam para discutir questões relacionadas. Zahra, Priem e Rasheed (2005), por exemplo, elencam a composição do quadro de diretores, a liderança e a cultura organizacional como fatores que podem estimular a ocorrência da fraude gerencial. A separação entre propriedade e controle, característica da corporação moderna, demanda atenção para o quadro de diretores, pois os acionistas, ao mesmo tempo em que delegam as decisões para os gestores contratados, procuram 
diversificar o risco dos seus investimentos, não dispondo de recursos para monitorar os gestores. Por sua vez, a ausência de acompanhamento por parte dos acionistas permite que os gestores ajam de forma oportunista, de acordo com seus interesses próprios. O comportamento ético também é considerado um fator capaz de influenciar as ações dos gestores da alta direção, bem como a cultura organizacional permissiva, em que as condutas ilegais são institucionalizadas como uma prática natural.

Entendendo que a má conduta organizacional torna-se arraigada nas organizações, MacLean (2008) busca no Interacionismo Simbólico uma compreensão mais ampla para explicar a natureza do relacionamento entre pressões, oportunidades e a má conduta organizacional. Essa compreensão mais ampla é necessária pelo fato de outras abordagens oferecerem explicações parciais, já que essas não consideram os esquemas cognitivos ou as manifestações culturais (linguagem, símbolos, imagens, estereótipos, entre outros) construídas e compartilhadas pelos membros da organização. A perspectiva interacionista simbólica se ancora em uma concepção de que o significado é central e os objetos sociais são construídos e reconstruídos pelos atores envolvidos de forma interminável em suas interações sociais (BLUMER, 1986). Nessa perspectiva, durante as interações sociais, os indivíduos não reagem às ações dos outros, mas, sim, interpretam-nas e, baseados no significado que a elas atribuem, agem no contexto social. A tradição interacionista simbólica inspirou os neoinstitucionalistas na argumentação de que a institucionalização, acompanhando a perspectiva de Berger e Luckmann (1996), é um processo de criação da realidade, e as instituições são sistemas de valores e normas que moldam os contextos sociais (SCOTT, 1992).

Nesse sentido, na esteira da perspectiva do interacionismo simbólico, assume-se que a má conduta organizacional, conforme MacLean (2008), é construída nas interações sociais que se efetivam nas organizações. Os resultados dessas interações são os frames ou quadros de significados compartilhados pelos membros que determinam suas escolhas e comportamentos. A cultura organizacional, entendida como o contexto social criado e compartilhado pelos membros da organização, se constitui como um fator de 
ligação entre o nível macro e nível micro para a análise do que ocorre nas organizações, incluindo-se os crimes corporativos. Esse entendimento vai ao encontro da proposta teórica de Vaughan (2007), que enfatiza o papel da organização e da cultura quanto à internalização da cultura e a normalização do comportamento desviante. Esquemas sedimentados na organização podem provocar o efeito de naturalização da má conduta organizacional, ou seja, as práticas enganosas podem ser vistas como um comportamental normal e aceitável naquela organização.

Em síntese, a análise deste caso pode dizer muito sobre os problemas originados das fraquezas do sistema mais amplo em que atuam as corporações, bem como das relações entre organizações, sociedade e governos. O caso é uma oportunidade para explorar com estudantes modelos alternativos de gestão que considerem a responsabilidade social corporativa para além do discurso retórico.

\section{Fechamento}

Este caso de ensino foi elaborado para estimular reflexões e debates sobre o dark side das organizações, neste caso, um crime corporativo. Ao articular os efeitos dos pressupostos, valores e sistemas organizacionais de um caso real com as características do paradigma capitalista, o caso potencializa um espaço para o debate de ideias relacionadas a formas alternativas para organizar o trabalho e a produção, e pensar sobre o consumo de bens. Diferentemente dos casos tradicionais, este caso provoca reflexõs sobre os quadros conceituais sobre corporações e a gestão. Trata-se de uma oportunidade para os estudantes refletirem no sentido de buscar práticas de gestão alternativas, ou modelos de oganizações com objetivos que possam trazer melhores condições de vida para a população em geral, ao invés de discutir modelos de gestão que reproduzem o capitalismo contemporaneo.

A VW lamenta o comportamento que levou ao caso do diesel, mas, de fato, o que ela fez foi: a) poluir o ambiente até 40 vezes o que foi reivindicado e (b) defraudar mais de meio milhão de clientes, e (c) enganar o governo órgãos reguladores. A despeito da admissão de sua culpa e das tentativas de omiti-la, a empresa, no mesmo dia que divulgou o acordo, anunciou 
também o recorde de vendas em 2016, ficando em $1^{\circ}$. Lugar no ranking mundial das montadoras. Seis executivos da empresa foram denunciados e deverão responder criminalmente pela fraude. Segundo estudo de revista especializada em meio ambiente, 5 mil mortes decorrentes de poluentes do diesel, por ano, na Europa, poderiam ter sido evitadas se as emissões fossem no mesmo nível apontado pelos testes e exigido pelo governo norte-americano. A conta para a empresa já ultrapassou US\$ 30 bilhões, que ela poderá recuperar com novos recordes em vendas. Para quem fica a conta de 5 mil mortes ao ano? Essas questões também devem fazer parte das reflexões de estudantes e pesquisadores da gestão. 


\section{REFERÊNCIAS}

BARLEY, S. R. Corporations, Democracy, and the Public Good. Journal of Management Inquiry, v. 16, n. 3, p. 201-215, 2007. DOI: 10.1177/1056492607305891

BAUCUS, M. S.; NEAR, J. P. Can Illegal Corporate Behavior Be Predicted? An Event History Analysis. The Academy of Management Journal, v. 34, n. 1, p. 9-36, 1991. DOI: $10.2307 / 256300$

BAUCUS, M.S. Pressure, Opportunity and Predisposition: a multivariate Model of Corporate Illegality. Journal of Management, v. 20, n. 4, p. 699-721, 1994. DOI: 10.1016/01492063(94)90026-4

BERGER, P. L.; LUCKMANN, T. A construção social da realidade. Tratado de sociologia do conhecimento. Petrópolis: Vozes, 1985.

BLUMER, H. Symbolic interacionism: perspective and method. Califórnia: University of California Press, 1986.

CAREY JR., C. W. An Essay from 19th Century U.S. Newspapers. Corporations and Big Business, 2011. Disponível em: <http://www.gale.cengage.com/pdf/whitepapers/gdc / Corporations $>$ Acesso em: 12 dez. 2011.

CLINARD, M. B. et al. Illegal Corporate Behavior. U. S.: Department of Justice, 1979. Disponível em: < https:/ / www.ncjrs.gov/pdffiles1 / Digitization/105519NCJRS.pdf> Acesso em: 20 nov. 2012.

DABOUB, A. J.; RASHEED, A. M. A.; PRIEM, R. L.; GRAY, D. A. Top Management Team Characteristics and Corporate Illegal Activity. Academy of Management Review, v. 20, n. 1, p. $138-170,1995$. DOI: $10.2307 / 258890$

ESCÂNDALO da Volkswagen: como o 'dieselgate' começou e as consequências. G1, São Paulo, 23/09/2015. Atualizado em 23/02/2018. Disponível em: <http:/ /g1.globo.com/ carros/noticia/2015/09/escandalo-da-volkswagen-veja-o-passo-passo-do-caso.html>. Acesso em: 26 fev.2018.

EWING, J. Audi Engineer Implicates Superiors in Diesel Case, Lawyer Says. New York Times, 21/08/2017. Disponível em: https: / /www.nytimes.com/2017/08/21/business / audi-volkswagen-diesel-emissions.html Acesso em: 10 jan.2018.

FOURNIER, V.; GREY, C. Na hora da crítica: condições e perspectivas para estudos críticos de gestão. Revista de Administração de Empresas, v. 46, n. 1, p. 71-86, 2006.

GOLDMAN, A.; TABUCHI, H.; EWING, J. F.B.I. Arrests Volkswagen Executive on Conspiracy Charge in Emissions Scandal. The New York Times, 09/01/2017. Disponível em: <https: / www.nytimes.com/2017/01/09/business/volkswagen-diesel-emissions-investigation-settlement.html>. Acesso em: 26 fev. 2018.

HOTTEN, R. Volkswagen: The scandal explained. BBC News, 10/12/2015. Disponível em: <https: / /www.bbc.com/news/business-34324772>. Acesso em: 26 fev. 2018.

JUSTIÇA alemã multa Volkswagen em 1 bilhão de euros no caso "Dieselgate". G1, 13/06/2018. Disponível em: <https://g1.globo.com/carros/noticia/justica-alema- 
multa-volkswagen-em-1-bilhao-de-euros-no-caso-dieselgate.ghtml>. Acesso em: 10 mar. 2019.

KRAMER, R. C. Corporate Criminality: the Development of an Idea. In: HOCHSTEDLER, E. (Ed). Corporation as Criminal. Beverly Hills: Sage Publications, 1984.

MACLEAN, T. L. Framing and Organizational Misconduct: A Symbolic Interactionist Study. Journal of Business Ethics, v. 78, p. 3-16, 2008. DOI: 10.1007/s10551-006-9324-x

MARQUET, D. VW CEO Blows More Smoke Over Diesel Fraud. Forbes, 15/01/2017. Disponível em: <https: / www.forbes.com/sites/ davidmarquet/2017/01/15/vw-blows-smoke/\#7976df7c529f>.

MCKENDALL, M. A.; WAGNER, III, J. A. Motive, Opportunity, Choice, and Corporate Illegality. Organization Science, v. 8, n. 6, p. 624-647, 1997. DOI: 10.1287 / orsc.8.6.624

MEDEIROS, C. R. O.; SILVEIRA, R. A.; OLIVEIRA, L. B. Mitos no Desengajamento Moral: Retóricas da Samarco em um Crime Corporativo. Revista de Administração Contemporânea, v. 22, n. 1, p. 70-91, 2018. DOI: 10.1590/1982-7849rac2018160310

MEDEIROS, C. R. O.; ALCADIPANI, R. Organizações que Matam: Uma Reflexão a Respeito de Crimes Corporativos. Organizações \& Sociedade, v. 24, n. 80, 39-52, 2017. DOI: $10.1590 / 1984-9230802$

MICHALOWSKI, R. J.; KRAMER, R. C. State-Corporate Crime and Criminological Inquiry. In: PONTELL, H. N. \& GEIS, G. L. (Ed.). International Handbook of White-Collar and Corporate Crime. Cap. 2, p. 200-219, 2007.

MICHALOWSKI, R. J.; KRAMER, R. C. The space between laws: the problem of corporate crime in a transnational context. Social Problems, v. 34, n. 1, p. 34-53, 1987. DOI: $10.2307 / 800728$

MON, W. Causal Factors of Corporate Crime in Taiwan: Qualitative and Quantitative Findings. International Journal of Offender therapy and Comparative Criminology, v. 46, n. 2, p. 183-205, 2002. DOI: $10.1177 / 0306624 X 02462005$

MORGAN, G. Images of organization. London: Sage, 1996.

PAYNE, B. K. White-collar Crime. The Essentials. Georgia: Sage Publications, 2012.

PEARCE, F.; TOMBS, S. Toxic Capitalism: Corporate crime and the Chemical Industry. Toronto: Canadian Scholars' Press, 1999.

PRESIDENTE da Volkswagen renuncia a cargo em meio a escândalo de poluição. Folha de S.Paulo, 23/09/2015. Disponível: <http://www1.folha.uol.com.br/mercado/2015/09/ 1685337-presidente-da-volkswagen-renuncia-a-cargo-em-meio-a-escandalo-de-poluicao.shtml>. Acesso em: 15 jan. 2018.

SCOTT, W. R. Organizations. Racional, Natural and Open Systems. 4. ed. New Jersey: Prentice Hall, 1992.

SEIB, C. Volkswagen's US boss: We totally screwed up. CNBC, 21/09/2015. Disponível em: <https: / / www.cnbc.com/2015/09/21/volkswagen-us-ceo-screwed-up-on-eca-emissions-diesel-test-rigging.html>. Acesso: 10 jan. 2018. 
SOROS, G. A crise do capitalismo global. Rio de Janeiro: Campus, 2001.

SZWAJKOWSKI, E. Organizational illegality: Theoretical integration and Illustrative Application. The Academy of Management Review, v. 10, n. 3, p. 558-567, 1985. DOI: $10.2307 / 258136$

THE UNITED STATES. Department of Justice. Fifth Superseding Indictment. 14 / 03 / 2018. Disponível em: < https: / / www.justice.gov/ opa/press-release/ file/1059821 / download>. Acesso: 10 mar. 2019.

THE UNITED STATES. Department of Justice. Volkswagen Senior Manager Sentenced to 84 Months in Prison for Role in Conspiracy to Cheat U.S. Emissions Tests. 06.12.2017. Disponível em: <https://www.justice.gov/opa/pr/volkswagen-senior-manager-sentenced-84-months-prison-role-conspiracy-cheat-us-emissions-tests>. Acesso: 10 mar. 2019.

VAUGHAN, D. Beyond Macro- and Micro-Levels of Analysis, Organizations, and the Cultural Fix. In: PONTELL, H.N.; GEIS, G.L. (Ed.). International Handbook of White-Collar and Corporate Crime. Cap. 1, p. 3-23, 2007.

VAUGHAN, D. The dark side of organizations: mistake, misconduct, and disaster. Annual Review Sociological, v. 22, p. 271-305, 1999.

ZAHRA, S. A.; PRIEM, R. L.; RASHEED, A. A. The antecedents and consequences of top management fraud. Journal of Management, v. 31, n. 6, p. 803-828, 2005. s: / / doi. org $/ 10.1177 / 0149206305279598$

\section{Indicações bibliográficas:}

ALEXANDER, C. R.; COHEN, M. A. Why do corporations become criminals? Ownership, hidden actions, and crime as an agency cost. Journal of Corporate Finance, v.5, p. 1-34, 1999. https: / / doi.org/10.1016/S0929-1199(98)00015-7

BANDURA, A. Moral disengagement in the perpetration of inhumanities. Personality and Social Psychology Review, v. 3, n. 3, p. 193-209, 1999. DOI: 10.1207/s15327957pspr0303_3.

BANDURA, A. Selective moral disengagement in the exercise of moral agency. Journal of Moral Education, v. 31, n. 2, p. 101-119, 2002. DOI: 10.1080/0305724022014322

BUTTERFIELD, K. D.; TRIVIÑO, L. K.; WEAVER, G. R. Moral awareness in business organizations: Influences of issue-related and social context factors. Human Relations, v. 50, n. 7, p. 981-1018, 2000. DOI: $10.1177 / 0018726700537004$

CORPORATE WATCH. Corporate critical research since 1996. Disponível em: <http// www.corporatewatch.org >. Acesso em: 20 jul. 2012.

GAULEJAC, V. de. Gestão como doença social. Ideologia, poder gerencialista e fragmentação social. Aparecida, SP: Ideias \& Letras, 2007. 


\section{DADOS DOS AUTORES}

\section{CINTIA RODRIGUES DE OLIVEIRA MEDEIROS cintia@ufu.br}

Doutora em Administração pela FGV/ EAESP

Instituição de vinculação: Universidade Federal de Uberlândia

Uberlândia/MG - Brasil

Áreas de interesse em pesquisa: estudos organizacionais, estudos críticos em administração, ensino e pesquisa em administração

Al. Antonio Scanapieco, 236 Jardim Karaiba Uberlândia/MG 38411-196 